\title{
Editorial
}

\section{It's all about presenting change}

Journal of Revenue and Pricing Management (2011) 10, 197-198. doi:10.1057/rpm.2011.10

The purpose of any journal is to present change. It all started with Littlewoods' rule (Littlewood, 2005) then Belobaba (1989) extended that with 'expected marginal seat revenue'. Later on, Wollmer (1992) formulated optimum booking limits and more recently dynamic programming has become the buzz word. This issue provides examples of change, whether it is methods of modelling consumer predictive behaviour or the fairness of brand class.

The practice articles section starts with an article by Westermann and Lancaster who present an interesting discussion piece on the pricing and decision support systems, advocating the advantages of integrating pricing with Revenue Management systems. Raskin and colleagues discuss a new data analytic approach to understanding and predicting consumer behaviour called Disjunctive Mapping (DM), previously introduced in 10.2 of the Journal of Revenue \& Pricing Management. The authors conclude with a discussion on the tools and methods DM employs, making some comparisons with more conventional statistical approaches, offering a case study and strategic implications. Hwang and colleagues address the problem of improving shareholder value in which companies primarily focused on cutting costs. However, continuing cost reductions has its limit necessitating attention on revenue as well. The authors propose a conceptual framework for pricing strategy development and execution in a competitive industry. The framework consists of a three-phased pricing management process and a set of implementation guidelines ensuring completeness, accuracy, responsiveness and flexibility.
In the research articles section, Kimes investigates customers' attitudes towards reservation policies. Reservations give restaurants the capability to select the most profitable mix of customers and help them better control their time. Reservations are not without problems because of the uncertainty associated with customers honouring their reservation and with the uncertainty associated with the length of time that customers will use the service. The study concluded that table-holding policies and credit card guarantees to be the most acceptable and fairest of the reservation policies. Kwon researches the problem of balancing web publishers for pay-per-view and pay per-click contracts for online display advertising, presenting an optimal strategy to determine the number of impressions to display for pay per-click advertisements.

Taylor and Kimes look at the fairness of brand class on Revenue Management and conclude that brand class does not impact perceptions of fairness of Revenue Management pricing practice strategies when controlling for familiarity and the provision of information, but hotels should focus on raising customer familiarity of their pricing strategies.

Pinchuk futures' article states that we will have a better understanding of how to optimize advanced predictive analytics. Instead of solving and implementing analytics the way we do today, we will learn how to capture much more value from new analytical successes and learn how to implement those advances into our business decisions with much more fluidity and timeliness. In conclusion, Varini reviews my book (and Una McMahon-Beattie) Revenue Management: A Practical Pricing Perspective and 
says, 'the best book I have read so far - a really excellent revenue management resource!' not that I am going to disagree or be biased.

\section{REFERENCES}

Belobaba, P. (1989) Application of a probabilistic decision model to airline seat inventory control. Operations Research 37: 183-197.
Littlewood, K. (2005) Forecasting and control of passenger bookings. Journal of Revenue \& Pricing Management 4(2): 111-123.

Wollmer, R. (1992) An airline seat management model for a single leg route when lower fare classes book first. Operations Research 40: 26-37.

Ian Yeoman Victoria University of Wellington, New Zealand. 